\title{
PERSPECTIVE
}

\section{Telemedicine Services of 'Shasthyo Batayon 16263' During COVID-19 Pandemic: Opportunities and Challenges}

\author{
Ahmed $\mathrm{NU}^{2 *}$, Rahman $\mathrm{MH}^{1}$, Roy $\mathrm{SS}^{1}$,Chowdhury $\mathrm{SA}^{2}$, Chowdhury $\mathrm{R}^{2}$ \\ ${ }^{1}$ Management Information System, Directorate General of Health Services, Ministry of Health \\ and Family Welfare, Dhaka, Bangladesh; ${ }^{2}$ Synesis HEALTH, Synesis IT Ltd, ICT Incubator, \\ Dhaka, Bangladesh
}

\section{Introduction}

Bangladesh has been implementing the digital health services to promote and protect public health, including telehealth, video-consultation, reporting even through data collection from the remote rural areas, monitoring, surveillance, human resource development including continued professional development etc. since long before the COVID-19 pandemic. ${ }^{1}$

The National Telehealth services is known as 'ShasthyoBatayon 16263' that was inaugurated by the honorable Minister, Ministry of Health and Family Welfare (MoHFW)on April 2016. The objectives are to provide low cost, efficient and timely delivery of general health care services in $24 / 7$ by medical doctors and counsellors. It is directly linked with existing health system for effectively responding the needs of citizen in Bangladesh. $^{2}$ 'Shasthyo Batayon' has been financed by the MoHFW through Directorate General of Health Services (DGHS) and implemented by Synesis IT, a private provider of eHealth services and pioneer in digital health services in Bangladesh. ${ }^{3}$ It is a collaborative partnership and integrated within operational plan for sustainable citizen's digital health services. ${ }^{4}$ The guidelines for telemedicine treatment protocol, advice/counseling, referral services and Standard Operating Procedures (SOP) were developed and approved for 'Shasthyo Batayon' (SB)by the DGHS. ${ }^{5}$ To avail 'Shasthyo Batayon' services, anyone can call to 16263 from any phone and access medical doctors and health information officers, who then provide consultation including treatment and counseling, referral services, emergency ambulance services and complaint management services according to the client's need. Clients are mostly referred to Government and private health facilities and also referred to medical specialists for higher level services in case of need. ${ }^{6}$ 'Shasthyo Batayon' has provided significant services

*Corresponding author: Dr. Nizam Uddin Ahmed, CEO, Synesis HEALTH of Synesis IT Ltd, ICT Incubator, 12, Karwan Bazar, Dhaka; e-mail:nizam1016@gmail.com,ORCID:0000-0002-9593-4636 during COVID 19 pandemic and able to deliver health services over 10 million citizens in Bangladesh including COVID-19 patient treatment and management of services. ${ }^{7}$ These services have also contributed to fill the gaps and as an alternative health service during COVID 19 pandemic. It has functioned as the "Digital Hospital" of Government and also directly contributed for strengthening Government's existing health systems with creative and innovative collaborations. ${ }^{8}$ It was promoted through commercials on TV, mobile phone, radio, newspapers, Facebook posts via official page, posters distributed to all public health facilities, robotic voice calls through mobile phones. ${ }^{9}$ It has been mention that, in july 2020, the Bangladesh has developed telemedicine guidelines, which will be a key enabler in of stering the growth of telemedicine which is being utilized by more healthcare practitioners and patients in a wide variety of forms. ${ }^{1,10}$ Citizens are able to access telehealth services and proven as the high impact digital health solutions for preventing diseases and saving lives. ${ }^{11}$

\section{Operational Model}

The following health services are provided by SB:

- Consultation by experienced medical doctors in $24 / 7$ for with treatment \& counselling;

- Provision of contact information of public and private hospitals, Specialists, clinics, blood bank and other health service providers as referral system;

- Provision of emergency ambulance services and booking facilities. This service is also linked with national emergency services (999);

- Registration of health service related complaints and auto escalate them to DGHS digital platform for redress; and 
- Collect information about emergency situations and notify relevant authorities.

SB operates on three 8 hourly shifts daily. There are 15 doctors and 8 Health Information Officer (HIOs) per shift during non-COVID-19 period. A five minutes call to 'Shasthyo Batayon' costs BDT 3.6 and generally this service received about 3,000 calls per day. Later on during COVID-19 from March 2020, call has increased significantly and 50 doctors and 10 HIOs, with a total of 150 medical doctors and 30 HIOs worked 24/7 from April to Dec 2020. SB expanded services to COVID-19 positive case management, maternal \& child health service to pregnant women, lactating mother, family planning, and adolescent's health services. ${ }^{12}$

'Shasthyo Batayon' services during COVID -19: On 8 March 2020, first case of COVID - 19 was identified in Bangladesh. After WHO declared a pandemic on 11March, 2020 the Government of Bangladesh declared general holiday with closures of offices, schools and businesses on $24^{\text {th }}$ of March in an effort to reduce community spread of COVID-19. Public health messages were communicated about COVID - 19 signs/symptoms, prevention and testing facilities through different media sources. As death toll related to COVID - 19 rose around the world and there was disruption of trade, travel and employment at both national and global level, the preventive measures such as lock down of large areas although effective, have resulted in heightened anxiety and loss of livelihood especially for the poor. This situation has created an opportunity to use telemedicine services such as 'Shasthyo Batayon'to fill an essential gap related to health information, diagnosis, treatment, counseling and support services for COVID-19 pandemic. ${ }^{13}$ In an effort to provide services to the citizens, the Ministry of Health and Family Welfare in Bangladesh moved to make 'Shasthyo Batyon' services toll free at the beginning of the epidemic and publicized the number (16263) through their different communication channels. As a result of COVID-19 pandemic, the calls to "Shasthyo Batayon" rose from about 4000 to 30,000 per day in one week and then to 80,000 per day (figure 1). Over 10.0 million

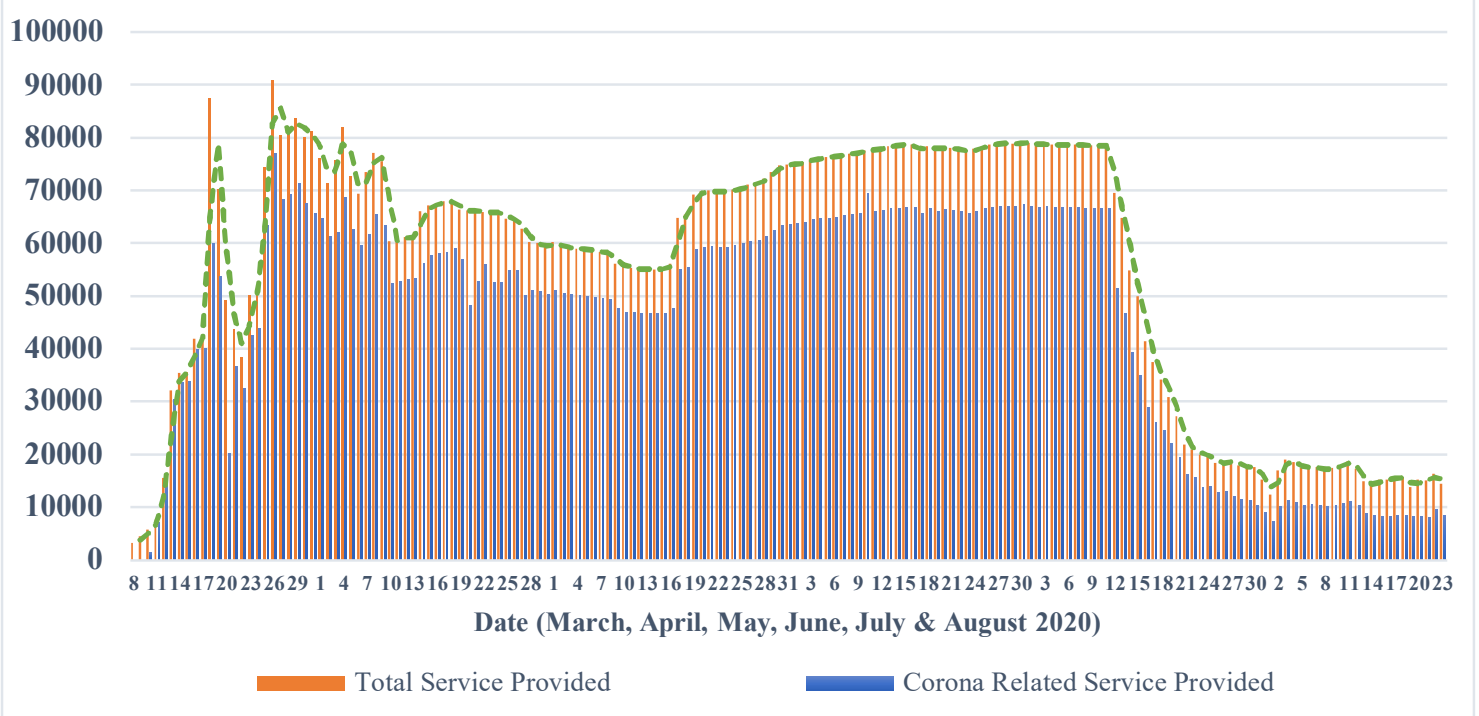

Figure 1: Daily calls from 08 March-23August2020

calls received by 'Shasthyo Batayon' from March 08 to 31August, 2020, the majority $(83.0 \%)$ were for COVID-19 related services. ${ }^{14,15}$ The total calls for doctor's consultation increased significantly during the epidemic (figure 2). In January, the total number of calls received was 16,820 but in March 'Shasthyo Batayon' received 60,181 calls. By August, call numbers were increased to $358,792 /$ month. 


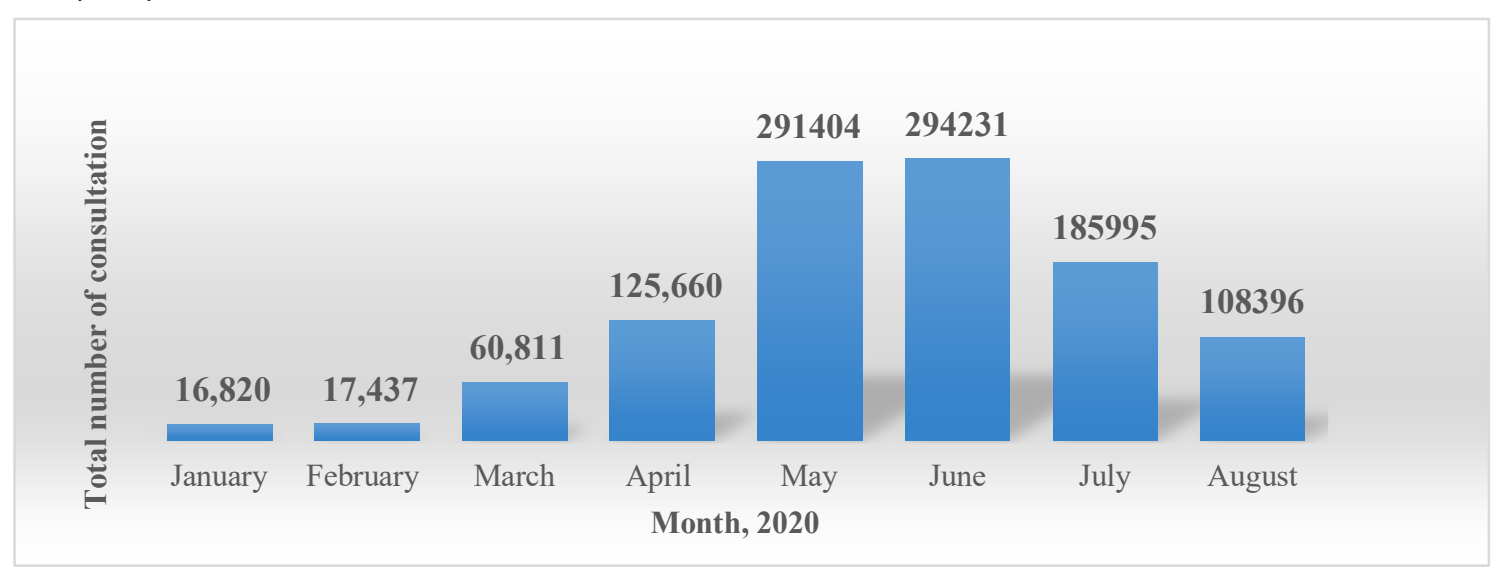

Figure 2: Number of doctor's consultations by month

When it was looked at the geographic areas that the calls came from we found that 'Shasthyo Batayon' received most calls from Dhaka division (41.3\%) and followed by Chattogram (17.1\%), Khulna (10.4\%) and regular 6.7\%. The least number of calls were received from Mymensingh $4.5 \%$ and Sylhet $2.5 \%$. There were two major types of call, one is for medical consultation and other for corona related information. The proportion of calls received from males were $72.8 \%$ while rest were from females. The proportion of calls for doctor's consultation by males ranged from $71.0 \%$ in Dhaka to $80.0 \%$ in Barisal (figure 4). When we analysed if there is any gender difference in the calls received by geographic area (figure 4,5 ) we found that proportion of calls are almost similar for medical consultation and corona related calls for both males and females.

When it was analysed the time trend of calls for doctor's consultation, it was to be we found that in January and February,2020, 65.0\% males and $35.0 \%$ females called for doctor's consultation. However, in the month of epidemic (MarchAugust 2020) the proportion of calls by female decreases to $22.0 \%$ and $27.0 \%$ respectively although the absolute number of calls may have increased (figure 6).

Among all the calls, 22,09,58 calls were made for $<5$ year old children, 50,46,62 calls were for 5-60 years of age and 4,63,967 calls for aged more than 60 years. The time trend of the calls by the age groups the calls were made for we found that the proportion of calls for the under 5year old children decreased during the epidemic from $31 \%$ to $6.0 \%$; the proportion of calls for 5-60 year olds increased from $67.0 \%$ to $89.0 \%$ and then $73.0 \%$ in the month of July-August; and the proportion of calls for elderly patients remain similar in March to April, 2020, however increased significantly in JulyAugust, 2020 21.0\%

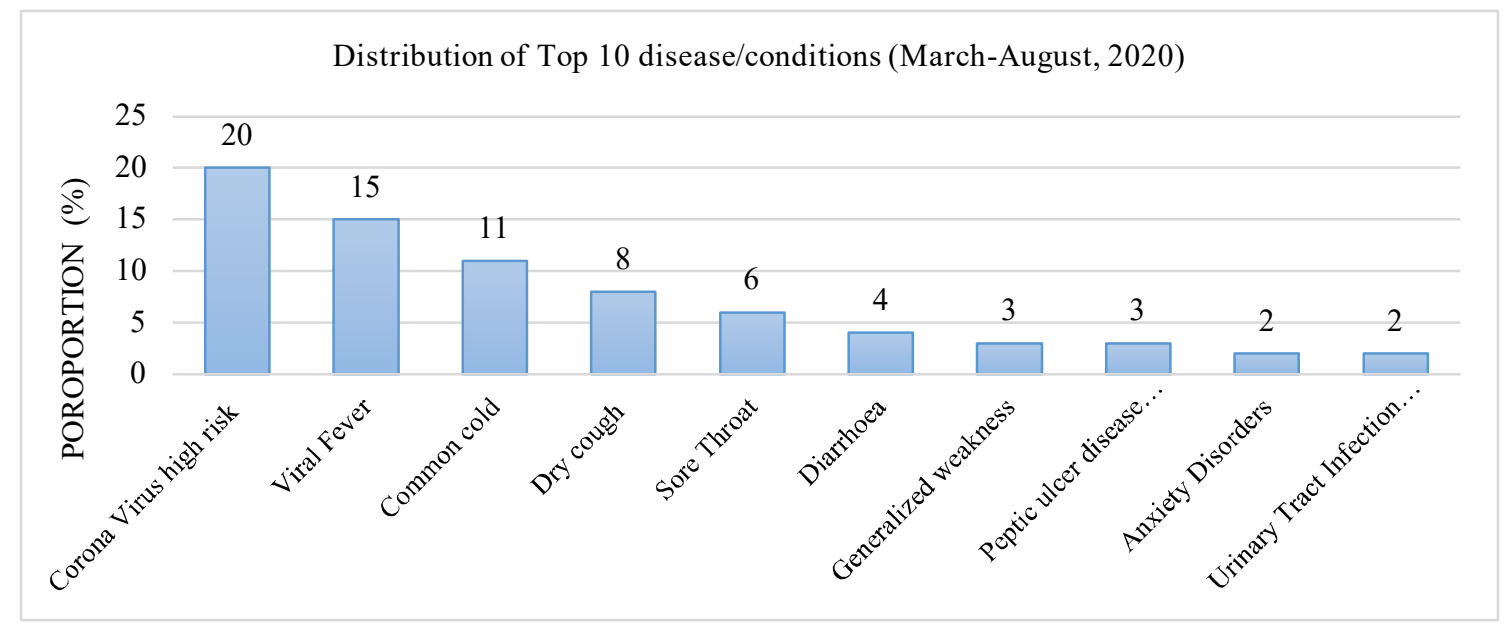

Figure 3: Distribution of Top 10 diseases or conditions 
'Shasthyo Batayon' followed a scoring system developed by the MoHFW to categorise Influenza like illness (cough, fever, sore throat, common cold) for clinical diagnosis of COVID-19 (figure 3). In total of 136,648 calls were received from the patients who were given a provisional diagnosis (common cold, viral fever, sore throat). During the epidemic period, $60.0 \%$ of call sought care respiratory infection (corona high risk, viral fever, common cold, dry cough and sore throat).
Source of information about $S B$ to the users. Social media, advertisements of SB from social media and outbound calls (OBD) reached people about $18.6 \%$. Interestingly SMS reached $19.4 \%$ users. Among the traditional media (TV, radio, newspaper), TV was the most important source of information about SB. Experience of calling SB was the most important source of information about SB (31.9\%).

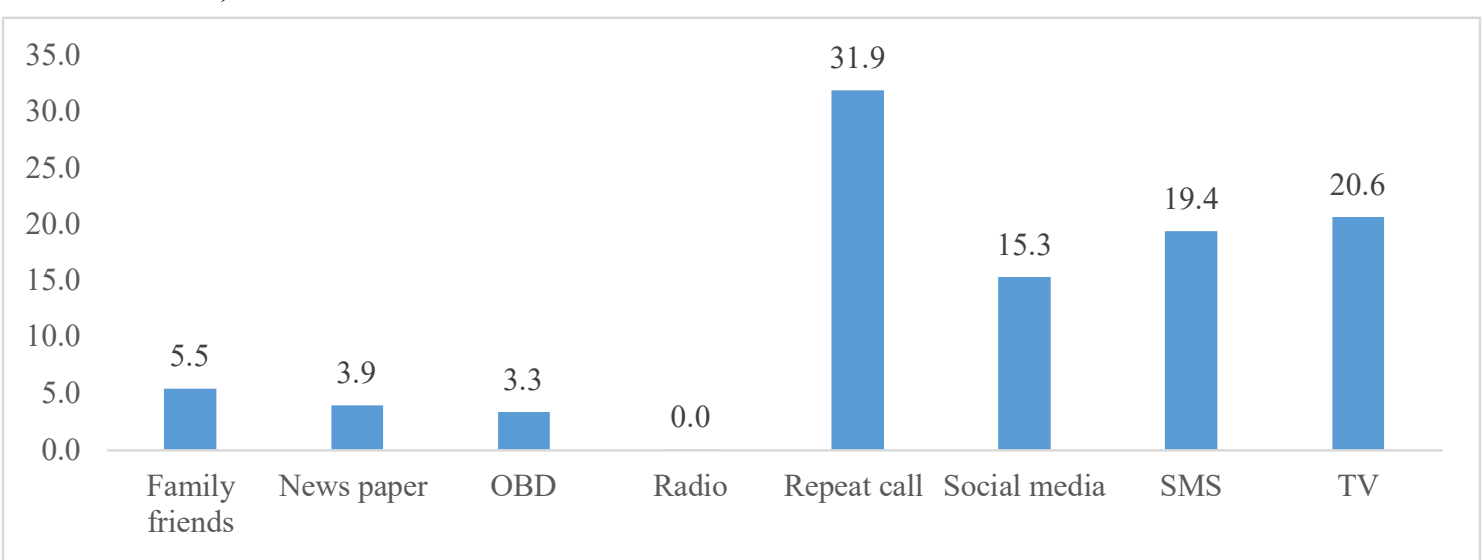

Figure 4: Source of information about 'Shasthyo Batayon' (doctor's consultation)

\section{Opportunities and Challenges:}

- Findings SB provides an opportunity to keep providing reliable information and support to a large number of people so that the existing health facilities are not overwhelmed;

- 'Shasthyo Batayon' services could safe guard the frontline health care providers as the number of people with uncomplicated COVID-19 symptom stop going to health facilities;

- Higher number of calls for primary healthcare other than COVID-19 indicating that users are not only seeking care for Corona virus infection they also relied on the teleconsultation services for their other diseases as well;

- The 'Shasthyo Batayon' services could combat the rapid rise in misinformation about COVID - 19 by providing transparent and evidence base guidance as more knowledge and information are revealed;

- It is important that 'Shasthyo Batayon' is promoted to districts beyond Dhaka and
Chattagram and through health professionals and social network so that the services could reach more people;

- However, with the sudden rise in daily call rates it is important to ensure that adequate resources are made available to maintain the service quality in terms of space, equipment, human resource and training;

- Implementation research should be funded along with the programme so that gaps in implementation can be addressed and lessons learnt can be documented for Bangladesh and other low resource setting for similar epidemics in the future if any; and

- 'Shasthyo Batayon' call centre platform could be a model for developing country perspective an alternative of primary healthcare during emergencies in an epidemic situation when face- to-face healthcare is not possible.

- Telemedicine service is able to provide low cost, reliable health services with privacy and earn respects from citizen and also contribute to Government's existing health system. 
Conflict of interest: Authors declared no conflict of interest

Funding: None

Submitted: $15^{\text {th }}$ September 2020

Final revision received: $15^{\text {th }}$ November 2020

Accepted: $25^{\text {th }}$ November 2020

Published: $1^{\text {st }}$ December, 2020

\section{References}

1. Rahman SMM, Hossain SM, Jahan MU. Digital health during COVID-19 pandemic and beyond. Editorial. Bangladesh Medical Res Counc Bull. 2020; 46:66-67.

DOI: $10.3329 /$ bmrcb.v46i2.49014

2. Directorate General of Health Services (DGHS); 2020, Dhaka.

URL: www.dghs.gov.bd/index.php/en

3. DGHS partnership collaboration for National Health services call center, 2020, DGHS, Dhaka.

4. Health Bulletin 2018.

URL:dghs.gov.bd/images/docs/Publicaations/HB \%202018\%20v2.pdf

5. National Tele Health Service Shastho Batayon 16263 guideline, 2020, DGHS, Dhaka. URL:dghs.gov.bd/images/docs/Notice/Health_C are_Rule.pdf

6. MIS, Directorate General of Health Services, Dhaka. 2020.

7. Daily and Monthly Report of Shastho Batayon, MIS DGHS. 2020.
URL: 16263.dghs.gov.bd/report/report.php

8. DGHS, Draft Digital Health strategy 2020-2025. Dhaka. Aug 2020 and World Health Organization. Draft global strategy on digital health 2020-2025. WHO, Geneva. July 2020.

9. Shastho Batayon 16263.

URL: www.facebook.com/shasthoBatayon

10. Bangladesh Medical \& Dental Council (BMDC). Telemedicine Guidelines. BMDC, Dhaka, July 2020.

URL:www.bmdc.org.bd/docs/BMDC_Telemedi cine_Guidelines_July2020.pdf

11. Rahman SMM, Hossain SM, Jahan MU. COVID-19 in Bangladesh: Measures for Containment. Editorial. Bangladesh Medical Res Counc Bull 2020; 46:01-02

DOI: $10.3329 /$ bmrcb.v46il.47460

12. Expansion of service of Shastho Batayon 16263. URL:www.bd-pratidin.com/city-news/2020/ 09/30/572067

13. Mahmood S, Hasan K, Caras MC, Labrique A. Global preparedness against COVID-19: We must leverage the powers of digital health. JMIR Public Health and Surveillance. 2020;6:e18980 DOI: $10.2196 / 18980$

14. Bangladesh Pratidin, Dhaka, Bangladesh. URL:www.bd-pratidin.com/health-tips/2020/ 10/ 30/582146

15. Daily COVID-19 Report of Shastho Batayon 16263, MIS, DGHS, 2020. 